\title{
Satisfying the hydra: the social imperative in medical school admissions
}

\author{
Kirsty Alexander and Jennifer Cleland \\ Centre for Healthcare Education, Research and Innovation (CHERI), University of Aberdeen, \\ Aberdeen, UK
}

In this issue of Medical Education, Marceau et al's concept analysis explores and delineates 'validity as a social imperative' by delving into the literature on assessment in healthcare professions education (HPE). Marceau et al tease out the usage of this multifaceted concept, how it is characterized, what led to its emergence in this form, and to consider what the consequences of the concept might be. They conclude that some of the findings stretch or exceed the limits of traditional validity frameworks: These include the responsibility of HPE to anticipate the "consequences of assessment decisions for individuals and society"; and to accommodate "society's increasing concern about the validity of assessment" (pX).

Reading the study, we were struck by the influence of 'validity as a social imperative' in the medical school admissions process. Around the world, entry to medical school characterises a high-stakes assessment - arguably the highest-stakes assessment a doctor will undertake in his or her career. The imperative to ensure that this assessment process is valid - selecting and rejecting the 'right' individuals on their ability and skills - sits at the core of western democracies' notion of meritocracy. Moreover, as "gatekeepers" to the profession, medical schools must keep a keen eye on who gains entry, particularly in systems with controlled numbers of students and high retention rates.

There is also a growing imperative that those assessed as suitable for medical school will go on to meet the healthcare needs of the whole population. This pressure stems from workforce crises and shortages in a number of countries. ${ }^{1}$ There is increasing concern that although current selection methods may select appropriately in terms of validity for individual competence, at the same time they may also actually "narrow" rather than increase diversity, thus perpetuating the recruitment of medical graduates who wish to work in certain specialties in mainly affluent, urban locations.

These concerns for 'social validity' at both the individual and societal level exemplify one aspect currently stretching traditional validity frameworks: the need to anticipate the future consequences of selection decisions for individuals and wider society. 
These imperatives have started to permeate through the planning, implementation and evaluation of admissions processes. For example, medical schools run specific programmes to admit applicants intending to practice in rural areas ${ }^{2,3}$ and increasingly use 'contextual admissions', a process in which the social background of the applicant is taken into consideration when assessing their attainment. ${ }^{4}$ Recent initiatives offer a more nuanced approach to selection: focused on individual ability; attentive to workforce needs; and mindful of systemic barriers facing some applicants.

Predicting optimal outcomes from these tools is complex however, and demands additional complexity and transparency. ${ }^{5,6}$ As a result, medical schools require resources to plan, implement, evaluate and disseminate initiatives. Moreover, they must be in the position to afford to take (wellcalculated) risks about who to select, and continue do so for long enough to muster sufficient change over sufficient years for longitudinal research to take root. This presents many challenges, particularly for medical schools situated in neoliberal Higher Education markets: from concerns about a public outcry when a "lesser" qualified applicant is accepted instead of one with an excellent grade point average, to the (perceived) risks of a jeopardised market position.

Moreover, monitoring the consequences of selection further than medical school (where impact really counts) requires joined-up data sources that can track doctors' career paths through further assessment phases in a robust and secure manner. Unfortunately, the availability of a foundation of high-quality longitudinal research data is often in scare supply, ${ }^{1}$ with some notable exceptions. ${ }^{7,8}$ The potential of longitudinal data sources is considerable, and leads us to echo XXX's calls for greater support of those responsible for assessment management and monitoring - not only on the ground at each local centre, but also to link in to national data repositories and research networks.

The second social imperative - society's increasing concern about the validity of assessment - is also starkly evidenced at the point of admissions. In our own context of the UK, with headlines questioning: "Why is there so little social diversity in medicine?"9 and warning of: "North Wales' GP shortage - escalating crisis", ${ }^{10}$ the public's eye is often fixed on the profession's gatekeepers to respond.

A range of stakeholders heavily invest in the admissions process. Anyone who has experienced medicine admissions - from either side - in recent years is well aware that applicants, potential applicants, their families and teachers expect transparent and credible selection criteria and processes, which they will rigorously study. Perceived inequities are often challenged with letters, lawyers and calls to the press. And caught in the midst of such a high-stakes and life-changing assessment, with fierce competition for places... why shouldn't they? 
These factors have resulted in politically-charged discussions about what constitutes 'fairness' in admissions, adding to concerns over the 'validity' of admissions processes. ${ }^{11}$ Debates surrounding what is 'fair' for the individual applicant versus/including what is 'fair' for overall society and the workforce make this a many-headed beast, which may challenge both the medical schools' and the profession's deeply held beliefs. ${ }^{12,13}$

Diverse socio-cultural factors and local pressures mean there is likely to be no blanket solution, and society's expectations of evidence of 'credible' assessment varies from context to context. 'Credible' may also mean 'comprehendible': as we strive for increased accuracy and predictive validity, the complexity of the process may become overwhelming and yet again diminish transparency. In this case, some small efforts may make a difference: in the UK, medical schools have responded to demands for clear and accessible information about their entry requirements by collating these into one booklet for comparison, with instructions for use and a universal layout. ${ }^{14}$

XXX's article suggests the consequents (direct results) of assessment procedures that are better planned and documented, and decisions that are shared transparently with society at large, include increased trust between the healthcare professions and those they serve. Trust is something that cannot be forced and these measures seem a reasonable act of cooperation. We hope medical admissions is already setting off down this path.

Finally however, it is perhaps also worth considering what "validity as a social imperative" means to the communities working within healthcare. Within UK medicine, students and trainees increasingly desire transparency, and challenge what they consider invalid rigidity in the career. ${ }^{15}$ So instead of a 'them' (society) and 'us' (healthcare professions) standoff, perhaps we should also consider the social imperatives 'inside' the professions in order to keep and build the trust of our future and current staff.

\section{References}

1. Gorman D. Matching the production of doctors with national needs. Med Educ. 2018;52(1):103-113.

2. Wenghofer EF, Hogenbirk JC, Timony PE. Impact of the rural pipeline in medical education: practice locations of recently graduated family physicians in Ontario. Hum Resour Health. 2017;15(1):16.

3. Kwan MMS, Kondalsamy-Chennakesavan S, Ranmuthugala G, Toombs MR, Nicholson GC. The 
rural pipeline to longer-term rural practice: General practitioners and specialists. PLoS ONE. 2017;12(7):e0180394.

4. Moore J, Mountford-Zimdars A, Wiggans J. Contextualised admissions: Examining the evidence. Cheltenham: Supporting Professionalism in Admissions (SPA); 2013.

5. Boliver V, Crawford C, Powell M, Craige W. Admissions in Context: The use of contextual information by leading universities. London: The Sutton Trust; 2017.

6. Griffin B, Porfeli E, Hu W. Who do you think you are? Medical student socioeconomic status and intention to work in underserved areas. Adv Heal Sci Educ. 2016;22(2):491-504.

7. Dowell J, Cleland J, Fitzpatrick S, McManus C, Nicholson S, Oppé T, et al. The UK medical education database (UKMED) what is it? Why and how might you use it? BMC Med Educ. 2018;18(1):6.

8. Kaur B, Carberry A, Hogan N, Roberton D, Beilby J. The medical schools outcomes database project: Australian medical student characteristics. BMC Med Educ. 2014;14(1):180.

9. Aziz, Z. Why is there so little social diversity in medicine? The Guardian. Available from: https://www.theguardian.com/healthcare-network/views-from-the-nhsfrontline/2017/mar/13/diversity-medicine-nhs-state-schools. [Published 13 Mar 2017; Accessed Feb 17, 2018].

10. BBC, North Wales' GP shortage - escalating crisis, medic warn. Available from: http://www.bbc.co.uk/news/uk-wales-40876801 [Published 10 Aug 2017; Accessed Feb 17, 2018].

11. Patterson F, Knight A, Dowell J, Nicholson S, Cousans F, Cleland J. How effective are selection methods in medical education? A systematic review. Med Educ. 2016;50(1):36-60.

12. Razack S, Hodges B, Steinert $Y$, Maguire M. Seeking inclusion in an exclusive process: discourses of medical school student selection. Med Educ. 2015;49(1):36-47.

13. Alexander K, Fahey Palma T, Nicholson S, Cleland J. "Why not you?" Discourses of widening access on UK medical school websites. Med Educ. 2017;51(6):598-611.

14. Medical Schools Council. Entry requirements for UK medical schools 2018. London; 2017.

15. UK State of Training Steering Group (UKSTSG). Report from the UK Shape of Training Steering Group. London; 2017. 